\title{
Schoenberg contra Schenker contra Schoenberg: polêmicas sobre dissonância, motivo e forma e as reconciliações possíveis
}

Schoenberg contra Schenker contra Schoenberg: polemics against dissonance, motive and form and their possible reconciliations

Norton Dudeque

(Universidade Federal do Paraná) Email:norton.dudeque@ufpr.br ORCID: 0000-0001-8229-5030 


\section{Resumo}

Este texto aborda uma das polêmicas mais importantes da teoria e análise musical do século $X X$. O embate entre Schoenberg e Schenker sobre a legitimidade das notas não harmônicas na música tonal, dissonâncias, a importância de motivo e forma. No texto busca-se discutir e esclarecer as concepções sobre estes assuntos e sua importância para as respectivas teorias analíticas de cada autor. Por fim, o texto apresenta as tentativas de reconciliação entre as duas tendências analíticas.

Palavras-chave: Schoenberg, Schenker, análise musical, teoria musical.

\section{Abstract}

This text addresses one of the most important polemics of 20th century music theory and analysis. The clash between Schoenberg and Schenker about the legitimacy of non-harmonic notes in tonal music, dissonances, the importance of motive and form. The text seeks to discuss and clarify the concepts on these subjects and their importance for the respective analytical theories of each author. Finally, the text presents the attempts to reconcile the two analytic trends.

Keywords:Schoenberg, Schenker, music analysis, music theory

\footnotetext{
1 Possui mestrado em Performance musical - University Of Western Ontario (1991), mestrado em Musicologia pela Universidade de São Paulo (1997), doutorado em Música (Ph.D.) - University of Reading (2002). Realizou estágio pós-doutoral no Kings College em Londres (2012). Atualmente é professor associado aposentado da Universidade Federal do Paraná e atua no Programa de Pós-Graduação em Música da UFPR. Tem experiência na área de Artes, com ênfase em Teoria e análise musical, atuando principalmente nos seguintes temas: análise musical, musicologia, teoria musical, música brasileira dos séculos XIX e XX.
} 
Schoenberg e Schenker se engajaram em uma disputa apaixonada pela legitimidade das dissonâncias na estrutura musical. A divergência teórica, no entanto, é indicativa de diferentes ideologias e abordagens à teoria e análise musical. A controvérsia sobre notas não harmônicas, como observado por Dahlhaus, seria quase sem sentido, se não tivesse revelado percepções distintas da estrutura musical (DAHLHAUS, 1987, p. 134) e questões ideológicas em defesa ou rejeição da música moderna. Além disso, a discordância entre Schoenberg e Schenker também revela diferentes abordagens da teoria musical e seu papel na compreensão do cânone e suas obras-primas, e especificamente na avaliação crítica da música.

O ataque de Schenker à música moderna em 1910 é veementemente expresso no primeiro volume do Kontrapunkt. Ao se referir às obras de Strauss, Schenker critica a suposta "falta de compreensão de técnicas existentes dos mestres" e continua enfatizando que se comparado às obras dos mestres, as obras da sua época seriam muito simples e até mesmo primitivas. Apesar da orquestração, gestos pomposos, polifonia e "cacofonia", Schenker declara que as melhores obras de Strauss - "em termos de um espírito verdadeiramente musical e da autêntica complexidade interna da textura, forma, e articulação" - ainda são inferiores a um quarteto de Haydn (SCHENKER, 1987, p. xxi). Um pouco mais adiante Schenker declara novamente sua preferência pelos mestres da música tonal tradicional - J. S. Bach, Haydn, Mozart, Beethoven, Schubert, Brahms- e as obras de Pfitzner, Humperdinck, Mahler e Reger são taxadas com a exclamação: "que pobreza!" (SCHENKER, 1987, p. Xxii; p. Xxiii). Schenker continuou a avaliar negativamente a teoria e a crítica da música da sua época, afirmando:

Como seria certo e justo prestar atenção à evolução da técnica composicional em vez de ficar divagando sobre o Zeitgeist! Mas este é o cerne da questão: o declínio de nossa arte se manifesta no fato de que todas as forças hoje falham em lidar com a música em termos puramente artísticos ... Não posso agora ficar calado sobre o fato de que as obras-primas da literatura musical são completamente deturpadas nos guias de concerto. Quanto mais os autores de tais análises nos asseguram que a estrutura de uma obra específica é clara para eles e fácil de compreender, mais o oposto é verdadeiro - ou seja, que eles nada sabem sobre ela. O que Kretzschmar, Riemann, Grove e outros escrevem sobre, por exemplo, as sinfonias de Beethoven é simplesmente errado e falso. Mil vezes falso! (SCHENKER, 1987, p. Xxiv - xxv).

Schenker também previu o desenvolvimento que suas teorias alcançariam posteriormente em Der freie Satz (1935). Sua crítica da teoria, e também da pedagogia musical, pretendia criar uma nova maneira de entender a música. O que Schenker buscava era um novo método que proporcionasse à teoria musical a possibilidade de identificar uma gramática particular, ou seja, um conjunto de regras ou estruturas fixas que explicassem o vasto repertório da música tonal. De fato, como Botstein observa, neste ponto reside a diferença crucial entre Schenker e Schoenberg. Ambos compartilhavam a convicção de que a música operava por leis análogas às da gramática linguística (BOTSTEIN, 1997, p. 16-19). A divergência entre os dois teóricos repousa na possibilidade de evolução dessa gramática. Para Schenker, era não evolutiva, para Schoenberg, ela sofreu uma evolução. 
Tanto Schenker quanto Schoenberg confiaram no conhecimento recebido da teoria musical do passado para legitimar suas respectivas autoridades para a avaliação crítica da música. Eles também compartilhavam a convicção de que a obra-prima tonal seria o modelo ideal para suas teorias. Para Schenker, o cânone recebido e fechado significava o repertório perfeito a partir do qual ele poderia sistematizar uma estrutura arquetípica comum a todas as obras-primas: a Ursatz (BLASIUS, 1996, p. 78). De fato, Blasius argumenta que "esta sistematização só é plausível quando concebida filologicamente, concebida em termos de um sistema de filiações em que uma árvore genealógica implícita de formas gramaticais arquetípicas surge entre um ancestral comum, a Ursatz, e os múltiplos textos do cânone" (BLASIUS, 1996, p. 78). Blasius continua seu argumento observando a característica ideal que a análise posterior de Schenker incorporou. Este ideal é refletido na retórica de Schenker da obra-prima e em suas análises posteriores onde Schenker fala dela em termos de uma síntese artística, "idealmente em sua incorporação simultânea de liberdade e disciplina máxima, substantivamente em sua reconciliação das dimensões musicais vertical e horizontal, historicamente em sua fusão da diminuição instrumental e do contraponto vocal" (BLASIUS, 1996, p. 94). A realização concreta desta abordagem sintética é realizada na notação gráfica de Schenker. Na verdade, Schenker afirmou que sua notação alcançou uma demonstração autossuficiente da estrutura das obras-primas musicais. Em seu Five Graphic Music Analyses, ele afirma que "a apresentação em forma gráfica foi agora desenvolvida a um ponto que torna um texto explicativo desnecessário" (SCHENKER, 1969, p. 9).

A reação de Schoenberg à crítica de Schenker à música moderna aparece em seu Harmonielehre de 1911. A disputa sobre notas não harmônicas que aparece no livro de Schoenberg e no segundo volume de Das Meisterwerk in der Musik (1926) de Schenker é um exemplo claro dessas formas divergentes de pensar. De acordo com a teoria tradicional, Schenker não teria tido dificuldade em rejeitar e explicar o que para Schoenberg era uma nova descoberta: as harmonias que ele encontrou nas obras de Mozart e Bach. Do ponto de vista de Schoenberg, essas harmonias são reconhecíveis apenas como sonoridades verticais locais; ou seja, elas são tiradas de contexto. Característica do debate polêmico é o reconhecimento dos acordes de sétima e nona como sonoridades legítimas por Schoenberg. Para ele, "o acorde de sétima e o acorde de nona apenas aconteciam em virtude de notas de passagem antes de serem aceitos no sistema" (SCHOENBERG, 1978 [1911], p. 323). Schenker, naturalmente, rejeitou este argumento, ele considerou a sétima como "uma suspensão ou uma nota de passagem que vem da oitava da tríade e se move para outra tríade ou permanece dentro do espaço de uma quarta dentro da mesma tríade"; e a nona "é uma suspensão ou uma nota vizinha" (SCHENKER, 2004 [1926], p. 15). Para Schenker, portanto, os acordes com sétima e nona não estão no mesmo nível hierárquico ao lado da tríade.

O argumento de Schoenberg a favor da emancipação da dissonância permitiu-lhe reivindicar uma orientação totalmente orgânica e negar a existência de notas não harmônicas. Ele afirma, portanto, que "é improvável que em um organismo bem construído, como uma obra de arte, aconteça qualquer coisa que não exerça absolutamente nenhuma influência em qualquer parte do organismo" (SCHOENBERG, 1978 [1911], p. 311). Para ele, não há nota 
menos importante do que as outras em uma obra musical, mesmo que fosse tradicionalmente explicada pela teoria da condução de vozes como uma dissonância que requer resolução para uma consonância.

A visão de Schoenberg de que a estrutura musical é percebida principalmente na superfície musical sugere que ele entende a emancipação da dissonância como produto de uma abordagem motívica. Assim, essa noção está coligada à sua orientação motívico-analítica que lhe permite encontrar motivos associados a notas não harmônicas. Dessa forma, a emancipação da dissonância se enquadra como um conceito que enfatiza a legitimidade e a importância das sonoridades de superfície. Aliada a essa noção, a abordagem principalmente motívica dos ensaios analíticos de Schoenberg corrobora a ideia de que "sonoridades emancipadas" podem ser vistas como resultado das combinações contrapontísticas de diferentes motivos e vozes.

Esclarecedor é o conceito de tonalidade de Schoenberg. Para ele, tonalidade é artificial e um produto artístico; ele afirma consequentemente que: "A tonalidade foi revelada não como um postulado de condições naturais, mas como o uso de possibilidades naturais; é um produto da arte, um produto da técnica da arte" (SCHOENBERG, 1975, p. 284). A declaração aponta claramente para a compreensão de Schoenberg da tonalidade como uma sistematização de elementos naturais de acordo com uma sintaxe específica. No entanto, sua rejeição do status de condição natural para a tonalidade não o impede de teorizar sobre o sistema tonal em bases acústicas. Schoenberg constrói sua derivação das escalas, diatônicas e cromáticas, sobre as notas fundamentais de uma série harmônica de Fá, Dó, e Sol (ver SCHOENBERG, 1978 [1911], p. 23-4; e SCHOENBERG, 1975, p. 270-273) em uma referência aberta ao Stufentheorie herdado de Simon Sechter (1788-1867). Schoenberg afirma que a tonalidade não é um fenômeno natural, mas simplesmente a exploração de sons musicais a fim de criar um efeito tonal que visa a percepção da tonalidade como um sistema formal eficaz que apresenta a qualidade de "completude ou fechamento" (SCHOENBERG, 1978 [1911], p. 27). Assim, o termo tonalidade é definido como "a arte de combinar tons em tais sucessões e harmonias ou sucessões de harmonias, de forma que a relação de todos os eventos com um som fundamental seja possível" (SCHOENBERG, 1975, p. 275-276). Assim, a cadência é o modelo para alcançar uma tonalidade e um efeito tonal definidos. As tríades de IV, II e V contêm duas notas características que distinguem uma tônica de sua dominante e subdominante. Em Dó maior, Fá impede que a região da dominante se estabeleça e Si evita que a região da subdominante seja introduzida. Portanto, o uso do 4ㅇ e 7ำ graus de uma escala na cadência IV (II) -V - I determina a tonalidade por representar regiões tonais específicas.

A compreensão de Schoenberg da tonalidade como artificial implica que a tonalidade não é o único meio de organizar o discurso musical. De acordo com Schoenberg: "é difícil conceber que uma peça musical tenha significado a menos que haja significado no motivo e na apresentação temática das ideias. Por outro lado, uma peça cuja harmonia não é unificada, mas que desenvolve seu motivo e material temático logicamente, deve, até certo ponto, ter um significado inteligente" (SCHOENBERG, 1975, p. 280). Consequentemente, o desenvolvimento motívico e temático adquire o status de necessidade. Na verdade, eles refletem a abordagem predominante da forma herdada da tradição da Formenlehre. Essa tradição não exclui a tonalidade como um tópico importante na análise musical, mas prioriza o motivo 
e as divisões formais como essenciais para definir a forma. Em última análise, a rejeição de Schoenberg de uma base natural para a tonalidade justifica sua técnica composicional e fornece uma base teórica para seu método analítico, que oferece um meio para expressar coerência e unidade musicais por meio de relações temáticas.

Uma vez que a tonalidade foi rejeitada como uma lei natural, as consonâncias e dissonâncias não são mais percebidas como sendo significativamente distintas umas das outras. Para Schoenberg, a distinção entre esses dois conceitos é uma questão de grau e não de uma espécie; ele diz que "as expressões 'consonância' e 'dissonância', que significam uma antítese, são falsas" (SCHOENBERG, 1978 [1911], p. 21). Schoenberg argumenta que a evolução histórica da música produziu uma percepção subjetiva desses fenômenos e, consequentemente, dissonâncias e consonâncias devem ser avaliadas de acordo com uma base acústica, ou seja, a partir da distância da nota fundamental na série harmônica. Deste ponto de vista, ambos os conceitos têm o mesmo grau de "naturalidade". Para Schoenberg, portanto, as consonâncias são "as relações mais próximas e simples com a nota fundamental" e as dissonâncias são "aquelas que são mais remotas, mais complicadas" (SCHOENBERG, 1978 [1911], p. 21). Em última análise, ele afirma que a emancipação da dissonância é o resultado lógico da evolução da música em que as relações tonais se tornaram mais complexas e menos compreensíveis. Assim, as dissonâncias adquiriram um caráter em que sua distinção depende de seu grau de compreensibilidade.

A partir dessa noção geral de consonância e dissonância, diferentes percepções da emancipação da dissonância podem ser inferidas. Primeiro, a emancipação da dissonância aborda questões técnicas sobre formação de acordes, resolução de dissonâncias e cromatismo; e em segundo lugar, refere-se a uma questão histórica, estética e ideológica no pensamento de Schoenberg. No que diz respeito à primeira percepção, foi apontado que a ideia de resolução não obrigatória de dissonâncias implicaria que a necessidade de resolução de dissonâncias tivesse sido abandonada em favor de um tratamento igual para ambos os conceitos (ROSEN, 1975, p. 34-35; DAHLHAUS, 1987, p. 121-122). Como esperado, a liberdade na resolução de dissonâncias permite um tratamento contrapontístico não tradicional das relações tonais mais complexas. Em outras palavras, a não resolução de dissonâncias torna a conexão entre acordes mais livre e evita o tratamento tradicional de dissonância-consonância. Ao defender a não resolução das dissonâncias, Schoenberg dá a entender que elas podem ser interpretadas como sonoridades independentes por si mesmas, uma vez que, segundo sua concepção, uma dissonância em um acorde tem uma função legítima sem depender exclusivamente de sua resolução, nem mesmo se considerada de acordo com o sistema tradicional de progressões e resolução de dissonâncias. $O$ argumento de Schoenberg sugere sua crença de que a estrutura musical é orgânica. Ele argumenta que as dissonâncias, como tudo o mais em uma obra musical, são parte de um todo orgânico e, como tal, têm ramificações para vários domínios musicais. Para ele, as dissonâncias "são consequências naturais e lógicas de um organismo. Além disso, este organismo vive tão vitalmente em suas frases, ritmos, motivos e melodias como nunca antes" (SCHOENBERG, 1975, p. 91).

Do ponto de vista de Schoenberg, notas não harmônicas são aquelas que não são reconhecidas como parte dos acordes tradicionais. Os acordes formados por essas notas não harmônicas não correspondem à sobreposição tradicional de terças e teóricos como Schenker, 
por exemplo, os excluem do sistema de classificação. Para Schoenberg, a classificação limitada de acordes com base nos primeiros harmônicos é artificial e arbitrária. Ele argumenta que mesmo em tal sistema limitado e restrito é possível derivar as notas não harmônicas das primeiras parciais da série harmônica. Schoenberg tenta explicar esses fenômenos usando a derivação de um acorde de nona (Dó-Mi-Sol-Ré). Ele argumenta que os harmônicos de uma nota Dó fundamental fornecem a tríade maior em Dó, e a nona (Ré) é derivada do Sol fundamental, intimamente associado ao Dó fundamental. Para ele, se tocarmos uma tríade Dó maior em um registro mais grave do piano, os seguintes harmônicos mais imediatos são parte do som: de Dó, Dó-Mi-Sol, de Sol, Sol-Si-Ré, de Mi, Mi-Sol\#-Si; assim, ao todo, Si, Dó, Mi, Ré, Sol, Sol\#. No entanto, um Ré em um acorde Dó-Mi-Sol é considerado não harmônico, estranho a essa sonoridade, mas pode-se entendê-lo como sendo diretamente derivado nesta tríade inicial (vide SCHOENBERG, 1978 [1911], p. 320). Assim, Schoenberg afirma que

Não existem, "sons estranhos à harmonia", mas somente estranhos ao sistema harmônico. Notas de passagem, adornos, retardos etc., tais como as sétimas e nonas, outra coisa não são que tentativas de incluir, nas possibilidades de complexos sonoros-portanto nas harmonias-, sonoridades parecidas aos harmônicos superiores situados mais distantes (SCHOENBERG 1978 [1911], p. 452).

A consequência desse pensamento é a decisão de Schoenberg de não reconhecer a existência de notas não harmônicas. Característica dessa abordagem são as harmonias que Schoenberg propõe como legítimas, por exemplo, como aquelas encontradas quando uma tríade de Dó maior é sustentada e sobreposta à uma escala de Dó maior em movimento contrário (Ex. 1a), que resulta em sonoridades expressas no Ex. 1b. Já no Ex. 1c, Schoenberg sobrepõe escalas em terças em movimento contrário à tríade de Dó maior. Naturalmente, Schoenberg defende estas sonoridades como acordes perfeitamente legítimos e verdadeiros.

Ex. 1a-c (Harmonielehre, Ex. 231a-c)

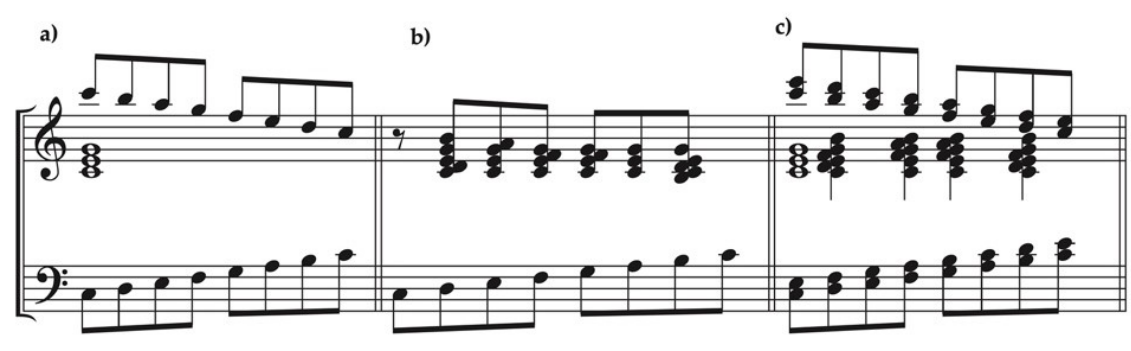

Também ilustrativos são os acordes que Schoenberg identifica na música de compositores do passado, especificamente do período clássico. Na Sinfonia em Sol menor de Mozart, K.V. 550, c. 150-152, Schoenberg reconhece as harmonias ilustradas no Ex. 2. 
Ex. 2 (de Harmonielehre, Ex. 233a, b)

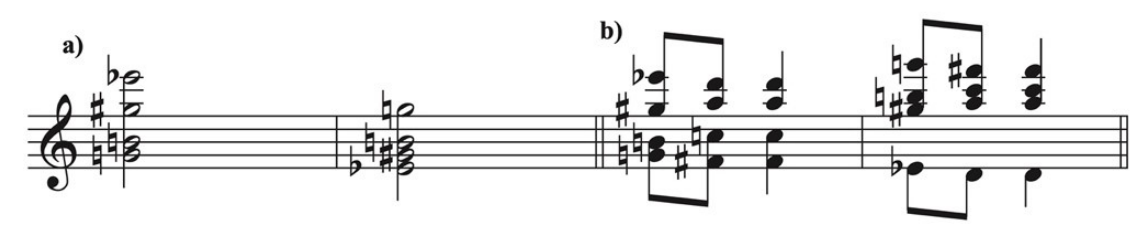

A resposta de Schenker às teorias de Schoenberg surge no seu ensaio Fortsetzung der Urlinie-Betrachtungen (Mais considerações sobre a Urlinie: II) publicado no Das Meisterwerk in der Musik, v. II. A seção "O intervalo dissonante sempre é um evento passageiro, nunca um som composto", denota a direção que a argumentação de Schenker toma na sua exposição. Inicialmente, Schenker expõe seu entendimento de notas de passagem e sua relação com a Urlinie. Para ele "uma progressão linear sempre pressupõe uma nota de passagem: não existe uma progressão linear sem uma nota de passagem, tampouco existe uma nota de passagem sem uma progressão linear" (SCHENKER, 2014 [1926], p. 70). Ele continua esclarecendo a origem contrapontística das notas de passagem na segunda espécie. Um caso em particular chama a atenção de Schenker, a nota de passagem por salto. Na Fig. 16 do ensaio, Schenker identifica no terceiro tempo do compasso uma dissonância legítima e resultante da simultaneidade entre nota de passagem e nota de contraponto:

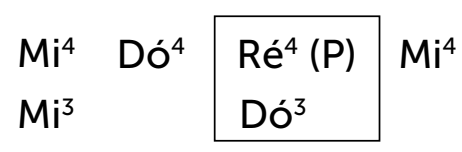

Apesar de reconhecer a dissonância como real, Schenker esclarece que ela só existe em função da "lei da nota de passagem dissonante". Ao comentar os exemplos de Schoenberg, reproduzidos acima, Schenker naturalmente se apoia na sua convicção sobre as notas de passagem. Em relação ao Ex. 1, Schenker comenta que as sonoridades encontradas por Schoenberg são apenas resultado da sobreposição de uma progressão de oitava e vozes internas que são sustentadas. Naturalmente, as notas de passagem, identificadas por Schenker, promovem um mero prolongamento da harmonia de Dó maior no exemplo. Finalmente, ao comentar a identificação das harmonias dissonantes na sinfonia de Mozart, Schenker afirma que a "sonoridade de nota-vizinha é, aqui, elevada rapidamente ao status de um acorde" e questiona se Schoenberg é tão inocente a ponto de ignorar o fato de que notas vizinhas não requerem preparação alguma? Por fim, e em diversas ocasiões no seu ensaio, Schenker questiona se Schoenberg realmente conhece a função de notas de passagem e notas vizinhas. Mas o ponto levantado por Schoenberg denuncia sua visão de reconhecer apenas uma dimensão hierárquica para a música, ou seja, a superfície musical.

Uma outra tentativa de explicar a importância das notas não harmônicas é o exemplo de Schoenberg tirado da Passio secundum Matthaeum (Paixão segundo São Mateus) BWV 244 
de J. S. Bach (ver Ex. 3, exemplo 266 do Harmonielehre). Na primeira frase do Coral de Bach em Si menor, Schoenberg afirma que as notas de passagem, no c. 2, terceiro e quarto tempos (Mi-Sol e Sol-Si), caracterizam a região da subdominante. Na segunda frase que leva à tônica (Si menor), Láł funciona definindo o relativo da tônica (Ré maior); entretanto, Láł, introduzido no c. 4, define Si menor como a tonalidade principal. A incerteza tonal entre maior e menor, inegavelmente, tem sua origem na indefinição da nota inicial. As notas de passagem, ao contrário do argumento de Schoenberg, não desempenham um papel importante na passagem; elas simplesmente implicam na tendência de uma tonalidade maior sobrepujar sua relativa menor. Alternativamente, Katz entende essas notas de passagem como meramente ornamentais e explica sua análise representada no gráfico A no Ex. 3. Ela explica que a progressão do primeiro acorde de Si menor para o acorde de Ré maior invertido é simplesmente uma progressão de tônica para a mediante. O acorde de Ré maior, por sua vez, é expandido por um prolongamento harmônico de I-V-I até o terceiro tempo do c. 2 (na fermata). As notas de passagem referidas por Schoenberg, são na realidade preenchimentos do arpejo de Ré maior, Ré-Fá\#-Lá. Assim, Mi-Sol no baixo e tenor, terceiro tempo do c. 1, conecta Ré-Fá\# para Fá\#-Lá, e Sol-Si-Mi (baixo, tenor e contralto) conecta Fá-Lá-Ré a Lá-Fá\#-(Ré, soprano) como uma V $\%{ }_{4}$ de Ré maior. Na segunda frase do coral, c. 3-4, Schoenberg argumenta que a nota Lá, a última colcheia no baixo do c. 3, deveria ser seguida de Ré maior. Katz, por sua vez, esclarece que o gráfico $B$ indica um movimento da mediante, Ré maior, para a dominante, Fá\# maior, onde o acorde de Mi menor no segundo tempo do c. 3, caracteriza uma nota de passagem entre Ré e Fá\#. Além disso, esta harmonia de subdominante tem na sua voz superior as notas Si e Mi que expandem a linha descendente de Ré a Dó\#. No gráfico C as notas de passagens são consonâncias, Dó\# como a terça de Lá maior, e Ré como a terça de Si menor, ambos funcionando como passagens na suas respectivas progressões. Finalmente, no gráfico D, é introduzido o acorde de supertônica (II), Dó\# menor com sétima. Este acorde somente prepara e enfatiza a conexão entre a mediante e a dominante funcionando como um apoio harmônico, enquanto o acorde de Mi menor (c. 3) é puramente contrapontístico (vide KATZ, 1947, p. 355-358). 

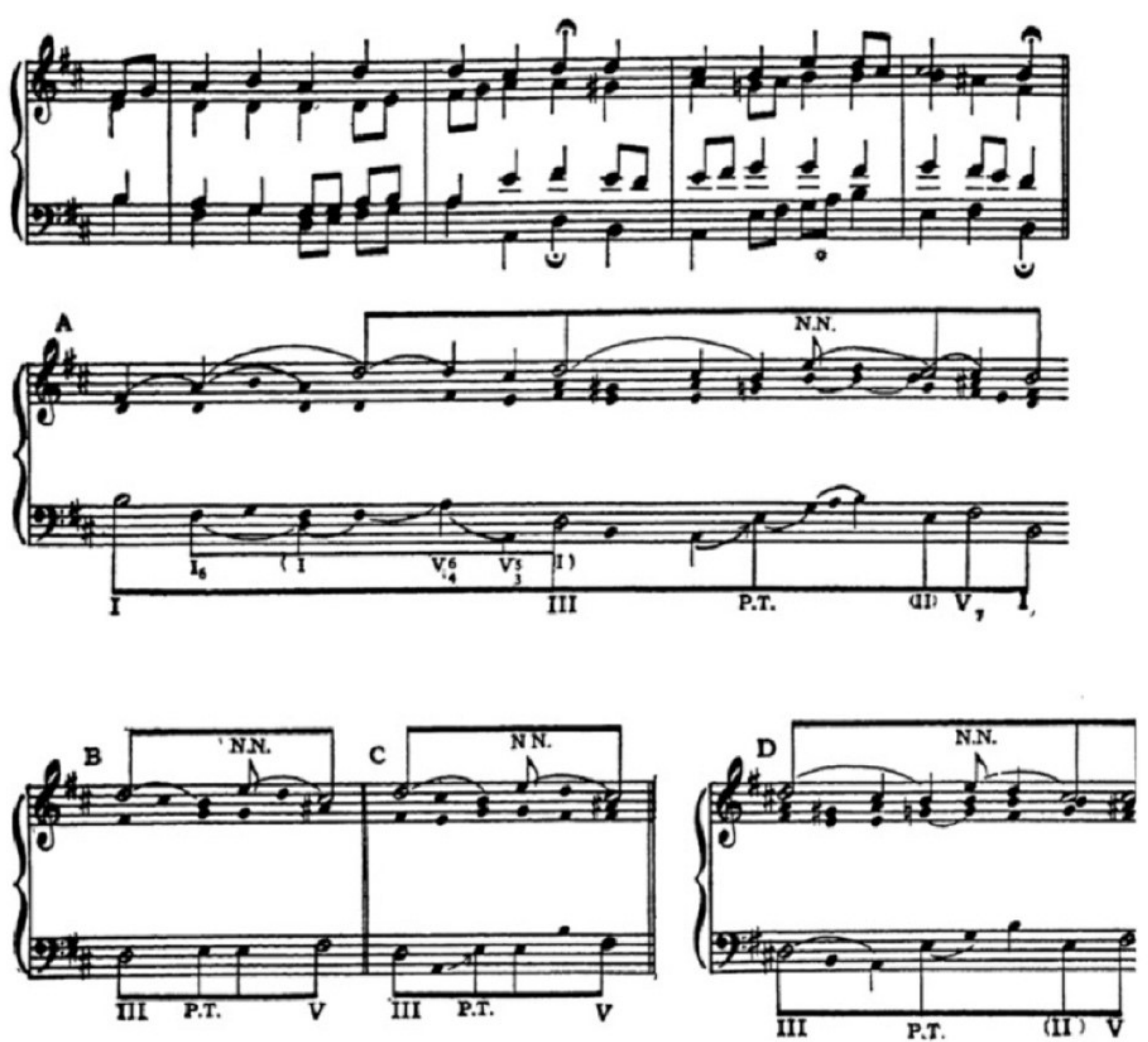

Portanto, Katz rejeita as opiniões de Schoenberg sobre notas não harmônicas, o que permite a ela afirmar:

A questão de saber se uma nota de passagem é um agente melódico ou harmônico é fundamental. Ainda mais vital para os problemas de estrutura musical é a afirmação de que ela não existe. Se ouvirmos todas as notas de passagem como orgânicas, como elementos integrados aos acordes com os quais elas aparecem, o movimento, a função essencial da disciplina contrapontística, é completamente obliterada. Nós não mais ouvimos horizontalmente, mas somente verticalmente, de acorde para acorde. Não há sensação de movimento dentro de um espaço bem definido no qual os fatores harmônicos e contrapontísticos demonstram suas funções individuais e combinadas, mas movimento de natureza indeterminada, que não tem significado estrutural nem coerência (KATZ, 1947, p. 358).

Tem-se argumentado que a decisão de Schoenberg de reconhecer apenas uma dimensão musical se deve em parte à sua posição histórica em particular, na qual ele tenta justificar seus conceitos musicais desse período mostrando sua ocorrência na música do passado (FORTE, 1978, p. 149-150). Para Straus, a consequência dessa interpretação equivocada é que Schoenberg interpreta erroneamente a noção tradicional das notas não harmônicas (STRAUS, 1990, p. 36). De fato, Schoenberg reconheceu que as harmonias que encontrou na sinfonia de Mozart são produtos da condução de voz e o resultado de notas de passagem (SCHOENBERG, 1978 [1911], p. 367-368). No entanto, ele argumenta que todas as notas são 
importantes em um contexto musical, e mesmo as harmonias incomuns que ele encontra na obra de Mozart podem ser consideradas importantes se vistas à luz das relações motívicas.

A insistência de Schoenberg em derivar suposições problemáticas, como a distinção entre consonâncias e dissonâncias e notas não harmônicas a partir da série harmônica, pode ser vista como um esforço para legitimar uma ideia sobre a qual o próprio Schoenberg não tinha certeza. Há uma posição ambivalente sustentada por Schoenberg em todos os seus escritos teóricos; esta posição se reflete em uma tensão latente entre a aceitação e a rejeição da teoria musical tradicional. Se, por um lado, ele rejeita um sistema tradicional de teoria musical prescritiva, por outro lado, ele aceita e adapta a teoria musical tradicional, mas para atender às suas próprias necessidades.

A diferença entre as respectivas abordagens de Schoenberg e Schenker à teoria e análise musical apresenta questões comuns e conflitantes. Por exemplo, uma das divergências mais diretas resulta da prática de Schoenberg em não reconhecer níveis distintos da estrutura musical. Ele está sempre preocupado com a análise da superfície musical, embora implique a compreensão e a presença de níveis distintos na estrutura musical, sejam harmônicos ou motívicos. Na verdade, Schoenberg indica, em alguns exemplos em Fundamentos, níveis distintos de percepção de relações motívicas (vide Exs. 45g, 121, 124 e 127 em Fundamentos de Composição Musical). Forte e Boss também abordaram a questão e podem esclarecer esse ponto de vista. Forte aplicou análise motívica a níveis estruturais distintos na música de Brahms. Para ele, a ideia de que o design motívico se expressa em diferentes níveis estruturais é particularmente reveladora da estrutura da música de Brahms. De acordo com Forte,

um motivo não se restringe a uma função de primeiro plano, mas pode se estender até o nível intermediário de uma composição. Os motivos têm vários significados e associações, dependendo do contexto. Quando eles interagem, os motivos podem apresentar semelhanças com outros motivos. Como um caso particular marcante, um motivo pode conter outro (FORTE, 1987, p. 196).

Boss, por sua vez, argumenta que Schoenberg implicava a noção de níveis estruturais em sua música atonal e em suas teorias. Ele afirma ainda que Schoenberg está, ao abordar a emancipação da dissonância, atacando "uma distinção estrutural-ornamental que afirma ser válida para todas as músicas, e não distinções apropriadas para peças, estilos ou compositores individuais" (BOSS, 1994, p. 207). Boss continua afirmando que, para Schoenberg, é essencial equivaler dissonâncias e consonâncias porque ele visa discutir o papel estrutural das dissonâncias em sua própria música "atonal" (BOSS, 1994, p. 210). Obviamente, Boss também está comparando as abordagens de Schoenberg e Schenker à análise musical. A partir dessa postura, parece apropriado considerar que Schoenberg está, de fato, levantando uma questão estética, seja na forma de teoria musical ou como prática composicional. Esta pode ser a razão para a afirmação de Dahlhaus de que a emancipação da dissonância é "um postulado estético, enraizado na oposição a todas as coisas ornamentais e sem função, ao invés de uma descrição da realidade musical" (DAHLHAUS, 1987, p. 135-136). 
Schenker e Schoenberg podem ter concordado sobre os princípios gerais que originam a forma musical. Em seu Harmonielehre, Schenker considerou a repetição um princípio importante para caracterizar o motivo e a forma. Os títulos de $\$ 4$ "Repetição como o Princípio Subjacente do Motivo" e 15 "Repetição como Criador da Forma" denotam a importância que teve para ele (SCHENKER, 1954 [1906], pp. 4-12). No entanto, na teoria madura de Schenker, a concepção de forma evoluiu para uma rejeição da noção de motivo como gerador de forma. Para Schenker, a forma resulta da interação das partes de acordo com uma hierarquia de níveis da estrutura musical. Portanto, Schenker rejeita as noções de forma que consideram os elementos da superfície musical como capazes de moldar a forma. Consequentemente, ele rejeitaria as noções de Grundgestalt; a realização dessa Grundgestalt através de variação progressiva, e, consequentemente, a tradição de Formenlehre. Nesse sentido, a visão de Schoenberg de que "os elementos maiores da forma são criados a partir do motivo" é inaceitável do ponto de vista Schenkeriano (SCHMALFELDT, 1991b, p. 233-236). Como resultado, o motivo no sentido tradicional não tem significado para Schenker e, portanto, ele rejeita

aquelas definições da forma da canção que tomam o motivo como ponto de partida e enfatizam a manipulação do motivo por meio de repetição, variação, extensão, fragmentação ou dissolução. Eu também rejeito aquelas explicações que são baseadas em frases, grupos de frases, períodos, pontos duplos, temas, antecedentes e consequentes. Minha teoria substitui tudo isso por conceitos específicos de forma que, desde o início, são baseados no conteúdo do todo e das partes individuais; isto é, as diferenças nos prolongamentos levam a diferenças na forma (SCHENKER, 1979, p. 131).

Portanto, no cerne da rejeição de Schenker está a tradição que Schoenberg segue. Isso é particularmente importante ao considerar as proposições de Schenker sobre a Ursatz. Para ele, todas as obras-primas compartilham o mesmo processo representado pela estrutura fundamental. Noções semelhantes se aplicam à forma, que se origina do nível de fundo por meio da técnica de Auskomponierung [composição]. A singularidade da obra emerge então nos eventos musicais nos níveis intermediários e de superfície (SCHMALFELDT, 1991b, p. 234; СОOK, 1989, p. 118). Smith vê a principal proposição schenkeriana de negar os tipos formais tradicionais como uma espécie de inversão de valores. Ele argumenta que "em vez de investigar a conexão que postulou entre forma e estrutura fundamental, Schenker simplesmente redefiniu a primeira em termos da última" (SMITH, 1996, p. 194) e, consequentemente, rejeitou a teoria formal tradicional. A discussão poderia ser resumida afirmando que a estrutura fundamental é uma contradição dos fenômenos do primeiro plano. A forma musical é percebida não como o desenvolvimento de uma estrutura subjacente, mas como uma expressão de todos os elementos musicais no nível de superfície. O particular, o individual, de cada composição é percebido neste nível e não na Ursatz geral.

Schoenberg pode ter concordado com Schenker sobre até que ponto a repetição de um motivo é necessária a fim de realizar a forma na música. Para Schoenberg, "um motivo aparece constantemente ao longo de uma peça: é repetido"; ele prontamente observa, no entanto, que a repetição por si só gera monotonia e a variação é, portanto, essencial (SCHOENBERG, 
1967, p. 8). Schoenberg manteve ao longo de sua carreira a convicção de que o particular poderia fornecer a lógica para o geral, ou seja, o motivo gera a forma. Na verdade, esse parece ser o argumento subentendido de Schoenberg. Ele afirma que a singularidade de uma obra é percebida no nível da superfície musical. Para alcançar essa singularidade, ele afirma que o compositor deve conceber "uma composição inteira como uma visão espontânea" (SCHOENBERG, 1967, p. 1), e que cada composição é um ato único de criação. Ele expressa essa ideia, dizendo que "um compositor - um verdadeiro criador - compõe apenas se ele tem algo a dizer que ainda não foi dito e que ele sente que deve ser dito" (SCHOENBERG, 1975, p. 165). Deste ponto de vista, a essência da ideia musical é única para cada obra; ou seja, cada composição deve ter uma nova ideia pertencente apenas a si mesma. Schenker, ao falar sobre organicismo na forma sonata, relata que ao

conceito de forma sonata, como tem sido ensinado até agora, falta-lhe precisamente a característica essencial - a do organicismo - cuja é determinada somente pela criação das partes a partir da unidade da tríade principal, i.e. pela elaboração da Urlinie e pelo arpejo do baixo.[...] Estes dissolvem a tríade de tônica em um movimento melódico da Urlinie e, ao mesmo tempo, alguns poucos acordes individuais são subdivididos novamente. Tal sentimento não pode ser criado artificialmente; em outras palavras, somente a criatividade baseada na improvisação pode conceder a unidade do processo composicional. Assim o conceito de forma sonata, se é para expressar o geral de maneira mais correta, necessita incluir o seguinte: o todo deve ser criado por improvisação, se é para não ser uma mera reunião de partes individuais e motivos de acordo com um conjunto de regras (SCHENKER, 2014 [1926], p. 123). ${ }^{2}$

Schenker parece estar de acordo com a noção de originalidade de Schoenberg. Para ele, a forma não deve surgir de uma conjunção de partes a partir de regras, mas, sim a obra deve ser criada de forma espontânea, e somente a improvisação representa tal concepção. Porém, a distinção entre a noção de Schoenberg de uma ideia única para cada composição difere da ideia de Schenker de uma Ursatz geral e adquire importância quando ambas as teorias são consideradas. Lado a lado, o que, para Schoenberg, é individual em cada composição, representa para Schenker a elaboração de uma fórmula geral válida para todas as obras-primas tonais.

Ilustrativo dessa discordância sobre a gênese da obra musical são as glosas de Schoenberg em sua cópia do primeiro volume de Der Tonwille (1921). ${ }^{3}$ Dunsby sugeriu que Schoenberg "mal sabia" o que Schenker pretendia em sua teoria posterior. Sua observação de que "a Urlinie de Schenker é, na melhor das hipóteses, um corte transversal do todo" (RUFER, 1961, p. 49)

2 vide também VAN DEN TOORN, 1996, p. 373.

3 Schoenberg possuía os seguintes livros de Schenker. Estas obras estão nos arquivos do Arnold Schoenberg Center em Viena. Ein Beitrag zur Ornamentik: als Einführung zu Ph. Em. Bach's Klavierwerken, umfassend auch die Ornamentik Haydns, Mozarts u. Beethovens etc. (Viena: Universal-Edition, 1903). Neue musikalische Theorien und Phantasien. Erster Band. Harmonielehre. (Stuttgart: J. G. Cotta'sche Buchhandlung Nachfolger, 1906). Neue musikalische Theorien und Phantasien. Zweiter Band. Kontrapunkt. Kontrapunkt. Erster Halbband. Cantus Firmus und zweistimmiger Satz. (Stuttgart: J. G. Cotta'sche Buchhandlung Nachfolger, 1910). Beethovens Neunte Sinfonie: eine Darstellung des musikalischen Inhaltes unter fortlaufender Berücksichtigung auch des Vortrages und der Literatur. 1. Ausgabe. (Viena: Universal-Edition, 1912). Der Tonwille, vol. 1. (Viena: Tonwille-Flugblätterverlag, 1921). 
leva Dunsby a concluir que "dificilmente seria compatível com um ponto de vista Schenkeriano a sugestão de que seções sejam possíveis" (DUNSBY, 1977, p. 30). Em outra anotação do artigo Der Tonwille de Schenker, Schoenberg expressou sua opinião sobre a Urlinie:

Tudo isso é descrição do valor mais duvidoso ... A Urlinie é a redução uniforme de todas as aparências à sua base mais simples e mostra não apenas as características das ideias trazidas à sua unidade comum, mas também que é em sua totalidade apenas um desenvolvimento da ideia básica. É a inspiração real do compositor, aquela totalidade, vista de uma só vez e ainda contendo tudo de substância, por meio da qual uma peça musical é concebida como um todo pelo autor (em DUNSBY, 1977, pp. 31-32).

Evidentemente, a ideia de Schenker em 1921 da linha fundamental ainda não estava totalmente desenvolvida. A observação de Simms de que "a Urlinie pode assumir a forma de um motivo: geralmente uma figura de graus conjuntos descendentes com alguns compassos de duração" é importante (SIMMS, 1977, p. 117); revela que, para Schenker, o "motivo fundamental" que produz a forma por meio de sua repetição ainda está intimamente associado às primeiras noções expressas em seu Harmonielehre (SCHENKER, 1954, p. 4ff). Schenker argumenta, em sua análise do Prelúdio em Mi, menor de Bach, que

é imediatamente evidente que, aqui, a Urlinie tem a forma do que é na sua essência um motivo de três notas, cujo impulso procriador dá origem a incontáveis repetições. Com certeza, tal motivo, uma vez que tem somente três notas, é por si mesmo nada mais do que uma elaboração (Auskomponierung) de qualquer espaço de uma terça, e sua repetição também é, por si mesma, nada mais do que repetição; mas aqui, quão distinta cada execução do motivo toma forma e quão diferente cada repetição surge! (SCHENKER, 2004 [1921], p. 34).

Como esperado, Schoenberg anotou na sua cópia do Der Tonwille afirmando que Schenker estava totalmente equivocado quanto à repetição. Schoenberg parece associar a Urlinie à repetição motívica, que para ele deveria ter variação. Stephan, ao discutir as anotações de Schoenberg sobre a análise em Der Tonwille, afirma que o aspecto importante a ser tirado das glosas de Schoenberg é que elas mostram que, para Schoenberg, nenhuma coerência musical é imaginável sem relação motívica. Além disso, a insistência de Schoenberg em encontrar motivos em configurações de acompanhamento indica que ele dá significado motívico além do significado tradicional de motivo, por exemplo, para o intervalo de uma segunda. Stephan resume: "O que é significativo é o caminho de motivo concreto, ou o menor elemento reconhecível como um motivo, para um elemento motívico mais abstrato: a relação intervalar, que está por trás do motivo e que assume um significado temático como aquele 
da forma rítmica abstrata" (STEPHAN, 1999, p. 136). De fato, Schenker, em um de seus últimos comentários sobre esta obra no seu texto, abre espaço para mencionar como Spitta, em 1873, comenta a elaboração motívica de Bach em sua peça (SCHENKER, 2004 [1921], p. 38).

O mal-entendido de Schoenberg sobre a linha fundamental de Schenker reflete as principais questões da teoria e análise musical. É evidente que, como Dale sugere, Schoenberg não acolheu um modelo teórico que pretendia ser um princípio geral de análise musical tonal. Na verdade, ele percebeu cada composição como única e tendo seus problemas particulares para análise. O método analítico de Schenker pretendia esclarecer e explicar a música de um repertório canônico de música tonal; suas análises eram a descrição da "verdade última" da estrutura musical das obras-primas. Schoenberg, ao contrário, viu uma análise específica como uma das "explicações possíveis" para a estrutura de uma obra, conforme relatado por Linke em 1912 (LINKE, 1999, p. 252-253). Além disso, a técnica redutiva desenvolvida por Schenker era inaceitável para Schoenberg. Ele não concordou com a exclusão das notas "não essenciais" da análise de uma obra específica; para Schoenberg não havia uma única nota que não tivesse influência na lógica musical (DALE, 1993, p. 27-28), embora, em seus textos posteriores, ele sugira o contrário. Essas questões podem ser vistas como reflexos da polêmica inicial sobre notas não harmônicas.

Tentativas de reconciliação entre as teorias analíticas de Schoenberg e Schenker foram realizadas por diversos autores. Críticas surgiram, por vezes apontando inconsistências, por vezes apontando as diferenças entre as duas abordagens. No entanto, textos que tentaram realizar esta conjunção de abordagens analíticas já se tornaram clássicos na área de teoria e análise musical. Este é o caso de Beyond Orpheus - Studies in Musical Structure de David Epstein publicado em 1979.

Do ponto de vista schoenberguiano, Epstein vê que a Grundgestalt se manifesta em diferentes níveis estruturais e que é improvável que sua influência se restrinja a um domínio musical particular. O principal desafio para Epstein é provar a validade da Grundgestalt nos vários domínios da estrutura musical. A fim de provar seu ponto, ele formula uma descrição da Grundgestalt que "denota uma configuração de elementos musicais que é significativa para a forma e estrutura de uma obra e se manifesta ao longo da obra em diferentes formas e em vários níveis estruturais". Notas ornamentais, elaborações do material básico modificam a Grundgestalt recorrente. Epstein está ciente, entretanto, de que Schoenberg se referia predominantemente a Grundgestalt como uma manifestação no nível da superfície. Ele, portanto, prontamente levanta a questão da noção de forma, que para ele, pode ser abstraída em "vários níveis removidos da realidade da superfície musical" (EPSTEIN, 1979, p. 19-20). Do ponto de vista schenkeriano, ou seja, com diferentes níveis hierárquicos, Epstein adota e aponta as seguintes contribuições: 1) a estrutura é clarificada por meio de uma perspectiva (hierárquica); 2) distinção entre estrutura e ornamentos emana desta perspectiva; 3) através da técnica de redução, a estrutura musical é elucidada em diferentes níveis; 4) harmonia resulta de progressões lineares e de contraponto; 5) movimento harmônico em grande es- 
cala denotando a "monotonalidade" de uma obra; 6) o conceito de Auskomponierung, ou seja, a elaboração da composição através do desdobramento do nível de fundo à superfície musical (EPSTEIN, 1979, p. 7-8).

Com uma abordagem envolvendo princípios analíticos schenkerianos e schoenberguianos, Schmalfeldt em 1991 propõe uma "reconciliação" entre teorias de forma musical, derivadas a partir das ideias de Schoenberg, e a teoria analítica de Schenker. O assunto principal abordado pela autora é relacionado à forma musical e como esta se expressa através da teoria analítica schenkeriana e schoenberguiana. Schmalfeldt começa por definir a origem da noção de totalidade da forma musical, do organismo musical, que para Schoenberg é "uma ideia única cuja individualidade seria um produto valioso de um ato verdadeiramente criativo" (SCHMALFELDT, 1991, p. 233). Já para Schenker todos os grandes compositores compartiIham uma única e mesma visão: a totalidade da estrutura fundamental (Ursatz). Assim para Schenker, a forma se origina no nível de fundo e se desenvolve a partir desta por meio da técnica de Auskomponierung, sua individualidade e sua forma emergem estritamente como fenômenos dos níveis de fundo e intermediário. Naturalmente, se Schenker acredita que a forma tem sua origem no nível de fundo, as noções de desenvolvimento motívico devem ser rejeitadas, incluindo a noção de Grundgestalt, variação progressiva e até mesmo o conceito de função formal das partes dentro de um todo (SCHMALFELDT, 1991, p. 233-234). Portanto, a argumentação se desenvolve a partir da noção de forma originada a partir da estrutura fundamental, que certamente tem seus elementos da forma, suas funções, suas unidades formais, desempenhando seus papéis em distintos níveis formais, adquirindo assim sua validade como proposta analítica. E a questão principal levantada se resume a: de qual maneira o processo da forma interage com a estrutura harmônico-contrapontística, ou talvez, algumas vezes conflite com a mesma? A fim de verificar sua compatibilidade, a autora compara as progressões lineares arquetípicas (Züge) de Schenker que determinam a forma, e os modelos formais schoenberguianos de sentença, período e de exposição de forma sonata.

Dez anos após a publicação de Schmalfeldt, Gianmario Borio apresenta um panorama sobre as duas teorias em questão em Schenker versus Schoenberg versus Schenker: The Difficulties of a Reconciliation. Borio foca seu texto na comparação entre análises do primeiro movimento da sonata op. 2, n. 1 de Beethoven, comparando as análises de Joseph Rufer (1954, p. I-II no Apendix) e de Schmalfeldt, e entre uma análise da sonata op. 57 de Beethoven realizada por Schenker e outra de Erwin Ratz (1951). A justificativa principal para Borio consiste no fato de que as duas vertentes analíticas compartilham conceitos básicos na sua fundamentação. Ilustrativo deste aspecto é a análise de Schenker em Der Tonwille da sonata op. 2, n. 1. Ali Schenker utiliza nomenclatura tradicional da morfologia musical. Por exemplo, ele se refere a primeiro tema, antecedente e consequente e modulação, segundo tema etc. Um exemplo que reforça a hipótese de uma fundamentação comum entre Schenker e Schoenberg. Mas Borio imediatamente observa que Schoenberg discordaria da análise de Schenker. Esta não considera as seções formais com suas respectivas funções (formais) dentro da dinâmica da macroforma. Por exemplo, o que Schenker considera como antecedente, para Schoenberg é toda a estrutura do tema, e o consequente de Schenker, é a transição para Schoenberg. No entanto, a ideia de obra orgânica, concepção cara para ambos, apresenta discrepâncias. Para Schoenberg o orgânico se manifesta por meio de 
um sistema de funções formais, com todas suas partes funcionando como um organismo vivo e organizado. Já para Schenker a coerência orgânica (organischer Zusammenhang) é a manifestação da fluência melódica na Urlinie. Aliás, a conclusão de Borio, sumarizada no texto, concerne este aspecto, ou seja, como as duas visões analíticas podem ser descritas. Para Borio "Schenker considerava composições de acordo com o modelo de vida, com sua tendência para a reprodução e expansão, enquanto para Schoenberg uma obra musical é uma criação linguística que, como tal, pode ser entendida somente pelo conhecimento das regras sintático-gramaticais nas quais é baseada" (BORIO, 2001, p. 273).

Em 2019, Arndt abordou as teorias organicistas de Schoenberg e Schenker, relacionando os domínios harmônicos, contrapontísticos e formais. Para ele, cada um destes domínios apresenta seu próprio modo recursivo sobre distintas dimensões do espaço musical abstrato, de tal maneira que a via lógica recursiva seja unida, consolidando a forma como se fosse um corpo. O primeiro destes domínios é o harmônico que é um mundo de relações tonais abstratas, mediadas por "sons fundamentais" (Grundtöne), que, pode-se dizer, geram as parciais e sons em acordes, escalas, regiões, e que são recursivos para outros sons (fundamentais). O domínio contrapontístico opera na dimensão de níveis hierárquicos, da superfície ao nível de fundo. O domínio formal (ou motívico) consiste na associação das partes através de repetição e variação (motívicas). Este domínio se centra na dimensão horizontal, no tempo. A linha de pensamento de Arndt procura assegurar a noção de "orgânico" em música, na forma musical, através das possíveis relações descritas acima. Assim, ele resume, no gráfico 1 , as interações destes domínios.

Gráfico 1: baseado em Arndt 2019, Exemplo 1, p. 7s

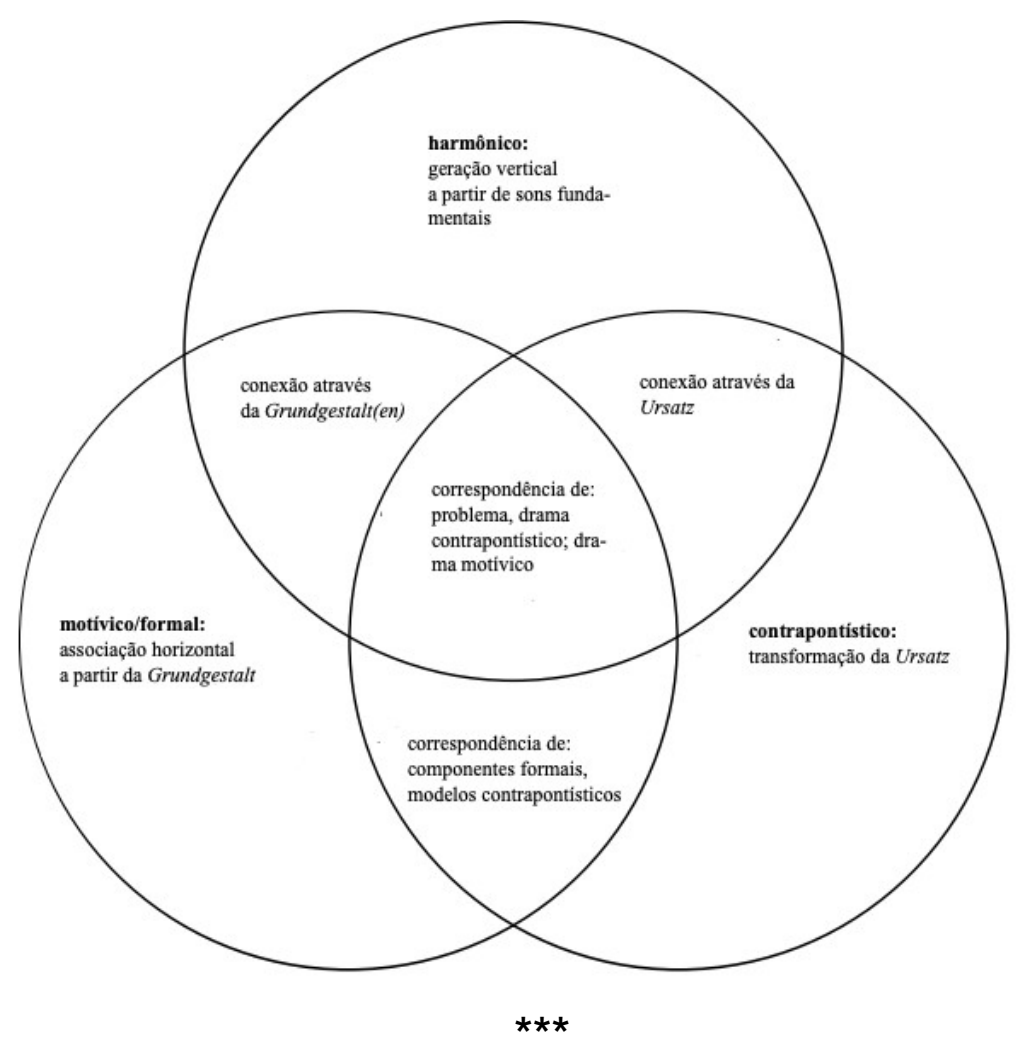


A discussão entre Schoenberg e Schenker sobre as notas não harmônicas, dissonâncias e sua legitimidade na estrutura musical são apenas a ponta do iceberg. Ela aponta diferentes percepções de forma musical, de métodos de análise, e do próprio entendimento crítico da música tonal, no caso de Schenker, e da música tonal e não tonal, no caso de Schoenberg. As tentativas de reconciliação destas metodologias analíticas procuram, quem sabe, um meio termo entre as ferramentas mais úteis de cada abordagem, e sugerem que mais tentativas de mediação entre as técnicas analíticas são possíveis. 


\section{Referências}

ARNDT, Matthew. Schoenberg - Schenker - Bach. Zeitschrift Der Gesellschaft Für Musiktheorie 16, no. 1 (2019), p. 67-97.

BLASIUS, Leslie David. Schenker's Argument and the Claims of Music Theory. Cambridge: Cambridge University Press, 1996.

BORIO, Gianmario. Schenker versus Schoenberg versus Schenker: The Difficulties of a Reconciliation. Journal of the Royal Music Association 126 (2001), p. 250-274.

BOSS, Jack. Schoenberg on Ornamentation and Structural Levels. Journal of Music Theory, 38 (1994), p. 187-216.

BOTSTEIN, Leon. Schenker the Regressive: Observations on the Historical Schenker. Musical Quarterly 86, no. 2 (2002), p. 239-247.

BOUCQUET, Kristof. Schenker and Schoenberg Revisited. Revue Belge de Musicologie 59, (2005), p. 193-203.

DAHLHAUS, Carl. Schoenberg and the New Music. Cambridge: Cambridge University Press, 1987.

DALE, Catherine. Tonality and Structure in Schoenberg's Second String Quartet, Op. 10. London: Garland Publishing, Inc., 1993.

DUDEQUE, Norton. Music Theory and Analysis in the Writings of Arnold Schoenberg (1874-1951). Aldershot: Ashgate, 2005.

DUNSBY, Jonathan. Schoenberg and the Writings of Schenker. Journal of the Arnold Schoenberg Institute 2, no. 1 (1977), p. 26-33.

EPSTEIN, David. Beyond Orpheus, Studies in Musical Structure. Cambridge: MIT Press, 1979.

GERLING, Cristina Capparelli, e Sauerbronn de Barros, Guilherme. Glossário de Termos Schenkerianos. Salvador: TEMA, 2020.

KARNES, Kevin C. Music, Criticism, and the Challenge of History. Oxford: Oxford University Press, 2008. 
KATZ, Adele. Challenge to Musical Tradition, A New Concept of Tonality. London: Putnam \& CO., 1947.

LINKE, Karl, e Barbara Z. Schoenberg. The Teacher. In Schoenberg and His World. Ed. Walter Frisch. Princeton: Princeton University Press, 1999, p. 250-260.

PELES, Stephen. Was Gleichzeitig Klingt: The Schoenberg-Schenker Dispute and the Incompleteness of Music Theory. Music Theory Spectrum 32, no. 2 (2010), p. 165-171.

RATZ, Erwin. Einführung in Die Musikalische Formenlehre: Über Formprinzipien in Den Inventionen Und Fugen J. S. Bachs Und Ihre Bedeutung Für Die Kompositionstechnik Beethovens. 3rd. editi. Viena: Universal Edition, 1951.

ROSEN, Charles. Schoenberg. London: Marrion Boyars, 1975.

RUFER, Joseph. Composition with Twelve Notes Related Only One to Another. London: Barrie \& Jenkins Limited, 1954.

RUFER, Joseph, e Newlin, Dika. The Works of Arnold Schoenberg: A Catalogue of His Compositions, Writings and Paintings. London: Faber \& Faber, 1961.

SCHENKER, Heinrich. The Masterwork in Music v. II. New York: Dover Publications, 2014 [1926].

SCHENKER, Heinrich. Der Tonwille. Edited by William Drabkin. Vol. I. Oxford: Oxford University Press, 2004.

SCHMALFELDT, Janet. Towards a Reconciliation of Schenkerian Concepts with Traditional and Recent Theories of Form. Music Analysis 10, no. 3 (1991), p. 233-287.

SCHOENBERG, Arnold. Trad. Roy E Carter. Theory of Harmony. London: Faber \& Faber, 1978.

Fundamentals of Musical Composition. Ed. Gerald Strang. London: Faber \&

Faber, 1967.

Style and Idea, Selected Writings of Arnold Schoenberg. Ed. Leonard Stein. London: Faber \& Faber, 1975.

SIMMS, Bryan R. New Documents in the Schoenberg-Schenker Polemic. Perspectives of New Music 16, no. 1 (1977), p. 110-124. 
SMITH, Charles J. Musical Form and Fundamental Structure: An Investigation of Schenker's Formenlehre. Music Analysis 15, no. 2-3 (1996), 191-297.

STEPHAN, Rudolf. Schoenberg and Bach. In Schoenberg and His World. Ed. Walter Frisch. Princeton: Princeton University Press, 1999, p. 126-140.

TOORN, Pieter C. Van Den. What's in a Motive? Schoenberg and Schenker Reconsidered. Journal of Musicology 14, no. 3 (1996), p. 370-399. 